\title{
Two alternative synthesis routes for MnZn ferrites using mechanochemical treatments
}

\author{
P.M. Botta ${ }^{\mathrm{a}, *}$, P.G. Bercoff ${ }^{\mathrm{b}}$, E.F. Aglietti ${ }^{\mathrm{c}}$, H.R. Bertorello ${ }^{\mathrm{b}}$, J.M. Porto López ${ }^{\text {a }}$ \\ ${ }^{\mathrm{a}}$ Instituto de Investigaciones en Ciencia y Tecnología de Materiales, INTEMA (CONICET-UNMdP), \\ J.B. Justo 4302, B7608FDQ Mar del Plata, Argentina \\ ${ }^{\mathrm{b}}$ Facultad de Matemática, Astronomía y Física, FaMAF (UNC), Medina Allende s/n, Ciudad Universitaria (5000), Córdoba, Argentina \\ ${ }^{\mathrm{c}}$ Centro de Tecnología de Recursos Minerales y Cerámica, CETMIC, (CIC-CONICET-UNLP) \\ Camino P. Centenario y 506 (1897), M.B. Gonnet, Argentina
}

Received 4 February 2005; received in revised form 9 May 2005; accepted 30 May 2005

Available online 16 August 2005

\begin{abstract}
Two different methodologies to synthesise $\mathrm{Mn}_{x} \mathrm{Zn}_{1-x} \mathrm{Fe}_{2} \mathrm{O}_{4}(x=0.5,0.65$ and 0.85$)$ are compared. In the first method, mechanochemically activated mixtures of elemental oxides were thermally treated at 1100 and $1200{ }^{\circ} \mathrm{C}$ under $\mathrm{N}_{2}$ atmosphere. In the second, previously obtained $\mathrm{MnFe}_{2} \mathrm{O}_{4}$ and $\mathrm{ZnFe}_{2} \mathrm{O}_{4}$ were well-mixed and treated at $1100{ }^{\circ} \mathrm{C}$ under $\mathrm{N}_{2}$ atmosphere. Both series of materials were characterised by $\mathrm{X}$-ray diffraction (XRD), vibrating sample magnetometry (VSM), scanning electron microscopy (SEM), electron probe microanalysis and density measurements. Through a two-step processing, both methods allowed to obtain MnZn ferrites of several compositions, which exhibited high saturation magnetisations and very low coercivities. In this way, in order to overcome some limitations of the conventional preparation technique, alternative synthesis routes for these ferrites are proposed in this study.
\end{abstract}

(C) 2005 Elsevier Ltd and Techna Group S.r.l. All rights reserved.

Keywords: C. Magnetic properties; D. Ferrites; Spinels; Mechanochemistry

\section{Introduction}

MnZn ferrites are ceramic materials widely used in the fabrication of transformers, frequency filters, magnetic recording heads, etc., due to their excellent properties such as high saturation magnetisation, high initial permeability, high resistivity and low losses [1]. The essential feature that makes improbable the replacement of these materials in the near future is the coexistence of high magnetisation and high electric resistivity, a combination that the magnetic metallic alloys do not exhibit [2].

As for most ceramic materials, the properties of MnZn ferrites are strongly affected by the synthesis method

\footnotetext{
* Corresponding author. Present address: Facultad de Física, Departamento de Física Aplicada (USC), Campus Universitario Sur, 15782 Santiago de Compostela, España, Spain. Tel.: +34 981 563100x14014; fax: +34 981520676 .

E-mail address: pbotta@usc.es (P.M. Botta).
}

(compositions, reactants and conditions), the forming process and the sintering parameters (temperature, additives and atmosphere). These ferrites are obtained by means of the traditional ceramic method, which comprises a solid-state reaction by calcination of oxides and/or carbonates. The method includes attrition milling of the reactants, followed by a first calcination between 900 and $1000^{\circ} \mathrm{C}$, wet milling, sieving, forming (uniaxial or isostatic pressing) and finally, sintering at $1300-1360{ }^{\circ} \mathrm{C}$ in a controlled atmosphere $[3,4]$. Moreover, several sintering additives (e.g. $\mathrm{B}_{2} \mathrm{O}_{3}$ ) are added in order to improve the density of the obtained materials, even through deteriorating their magnetic properties $[5,6]$. This multi-step processing often defines the quality of the obtained ferrites, limiting their applications. The poor reproducibility, the contamination problems and the use of high temperatures are the main disadvantages of the traditional method. For this reason, in the last years, novel synthesis techniques have been developed in order to satisfy 
the current requirements of microstructure control and processing efficiency. These alternative methods generally involve preparative techniques by wet routes, like thermal decomposition of metallic carboxylates [7,8], sol-gel [9], hydrothermal synthesis [10] and microemulsion [11].

Mechanochemistry and mechanical activation have been applied in the last decades as tools to synthesise materials from reactive solid-state systems, especially in those cases where the reactants do not exhibit the necessary reactivity or when the formation of metastable phases (not obtainable by conventional methods) is required [12]. Mechanical activation provides mechanical energy to the reactive solids that can be accumulated through plastic deformation in crystals, generation of point and extended defects in the crystalline structure and formation of new surfaces. All of these changes produce high-reactivity regions in the reactants, facilitating the occurrence of reactions and transformations in solids $[13,14]$.

Previous works about the application of mechanochemistry to MnZn ferrites synthesis are rare. Such investigations deal with the effects of mechanochemical treatments on the cation distribution in the crystalline ferrite structure, comparing mechanosynthesised $\mathrm{Mn}_{0.5} \mathrm{Zn}_{0.5} \mathrm{Fe}_{2} \mathrm{O}_{4}$ with that conventionally obtained $[15,16]$. In this work, two preparation routes for $\mathrm{Mn}_{x} \mathrm{Zn}_{1-x} \mathrm{Fe}_{2} \mathrm{O}_{4}(x=0.5,0.65$ and 0.85) using a combination of mechanical and thermal treatments were studied. The central objective is to find a simpler synthesis method for these soft magnetic ferrite materials.

\section{Experimental}

\subsection{Preparation of materials}

\subsubsection{Series $A$}

This series of samples was prepared by mixing $\mathrm{MnO}$, $\mathrm{ZnO}$ and $\mathrm{Fe}_{2} \mathrm{O}_{3}$ (hematite) in three different proportions, according to Table 1 . The used reactants were $\mathrm{MnO}$ powder (Aldrich, 99.0\%, particle size lower than $44 \mu \mathrm{m}$ ), $\mathrm{ZnO}$ powder (Mallinckrodt, 99.0\%, particle size lower than $44 \mu \mathrm{m}$ ) and $\mathrm{Fe}_{2} \mathrm{O}_{3}$ powder (Mallinckrodt, $98.5 \%$, particle size lower than $1 \mu \mathrm{m})$. The mixtures were treated for $1 \mathrm{~h}$ in a planetary ball-mill Fritsch Pulverisette 7, using ( $45 \mathrm{ml})$ vials

Table 1

Compositions of the ferrites prepared by both methods A and B

\begin{tabular}{ll}
\hline Molar composition & \\
\hline Series A & \\
$0.5 \mathrm{MnO}-0.5 \mathrm{ZnO}-\mathrm{Fe}_{2} \mathrm{O}_{3}$ & $\mathrm{~A} 50$ \\
$0.65 \mathrm{MnO}-0.35 \mathrm{Zn}-\mathrm{Fe}_{2} \mathrm{O}_{3}$ & $\mathrm{~A} 65$ \\
$0.85 \mathrm{MnO}-0.15 \mathrm{ZnO}-\mathrm{Fe}_{2} \mathrm{O}_{3}$ & $\mathrm{~A} 85$ \\
$\mathrm{Series}$ & \\
$0.5 \mathrm{MnFe}_{2} \mathrm{O}_{4}-0.5 \mathrm{ZnFe}_{2} \mathrm{O}_{4}$ & \\
$0.65 \mathrm{MnFe}_{2} \mathrm{O}_{4}-0.35 \mathrm{ZnFe}_{2} \mathrm{O}_{4}$ & $\mathrm{~B} 50$ \\
$0.85 \mathrm{MnFe}_{2} \mathrm{O}_{4}-0.15 \mathrm{ZnFe}_{2} \mathrm{O}_{4}$ & $\mathrm{~B} 65$ \\
\end{tabular}

and $15 \mathrm{~mm}$ diameter balls made of Cr-steel and a ball-topowder mass ratio of 22 . A rotation speed of $1500 \mathrm{rpm}$ was used.

The activated powders were compacted as $6 \mathrm{~mm}$ diameter and 1-2 $\mathrm{mm}$ thick disks, using a uniaxial press. After that, thermal treatments were performed under flowing $\mathrm{N}_{2}$ atmosphere in an electric furnace at 1100 and $1200{ }^{\circ} \mathrm{C}$.

\subsubsection{Series $B$}

In this case, the mixed $\mathrm{MnZn}$ ferrites were prepared starting from a mechanical mixture of both $\mathrm{ZnFe}_{2} \mathrm{O}_{4}$ and $\mathrm{MnFe}_{2} \mathrm{O}_{4}$ ferrites with the same compositions as Series A (Table 1). $\mathrm{ZnFe}_{2} \mathrm{O}_{4}$ powder was previously obtained by calcination of a $\mathrm{ZnO} / \mathrm{Fe}_{2} \mathrm{O}_{3}$ activated sample at $700{ }^{\circ} \mathrm{C}$ for $1 \mathrm{~h}$ in air. $\mathrm{MnFe}_{2} \mathrm{O}_{4}$ powder was obtained by heating of a $\mathrm{MnO} / \mathrm{Fe}_{2} \mathrm{O}_{3}$ milled sample at $1200{ }^{\circ} \mathrm{C}$ for $1 \mathrm{~h}$ under $\mathrm{N}_{2}$ atmosphere. The details of the synthesis of both ferrites are described elsewhere [17].

In order to obtain $\mathrm{Mn}_{x} \mathrm{Zn}_{1-x} \mathrm{Fe}_{2} \mathrm{O}_{4}(x=0.50,0.65$ and 0.85 ), three mixtures of $\mathrm{ZnFe}_{2} \mathrm{O}_{4}$ and $\mathrm{MnFe}_{2} \mathrm{O}_{4}$ were prepared according to Table 1 . The mixtures were milled in the planetary ball-mill Fritsch Pulverisette 7, using vials and balls made of $\mathrm{Si}_{3} \mathrm{~N}_{4}$ with a ball-to-powder mass ratio of 4 and a rotation speed of about $1000 \mathrm{rpm}$. After the first $2 \mathrm{~min}$ of milling, 2-propanol was added, continuing the treatment for 10 more minutes. These milling conditions were selected with the intention of producing a homogenous mixture of both solid components, without provoking significant structural damage. Finally, the milled reactive powders were dried at $80{ }^{\circ} \mathrm{C}$ in a laboratory stove.

In a similar way to that used for Series A, compacted powders were submitted to thermal treatments at $1100{ }^{\circ} \mathrm{C}$, using $\mathrm{N}_{2}$ atmosphere.

\subsection{Characterisation of materials}

All the samples were characterised by X-ray diffraction (XRD), vibrating sample magnetometry (VSM) and scanning electron microscopy (SEM).

The XRD patterns were made in a Philips 1830/00 diffractometer, with Co $\mathrm{K} \alpha$ radiation at $40 \mathrm{kV}$ and $30 \mathrm{~mA}$. Lattice parameters $(a)$ of the synthesised materials were calculated from the corresponding XRD patterns, measuring the position of the (3 11 l) diffraction peak with a precision of $0.005^{\circ} 2 \theta$. This means an absolute error of $0.001 \AA$ in the determination of $a$, which gives a relative error of about $0.010 \%$. Magnetic hysteresis loops were performed in a LakeShore 7300 magnetometer, coupled to an electromagnet with a maximum magnetic field of $15 \mathrm{kOe}$. Micrographs of fracture surfaces of the synthesised materials were taken with a Philips 505 scanning electron microscope, equipped with a electron probe microanalyser (EPMA). Prior to the observation, the samples were coated with gold. Densities of the sintered materials were measured by the Archimedes method, using distilled water as immersion liquid. 


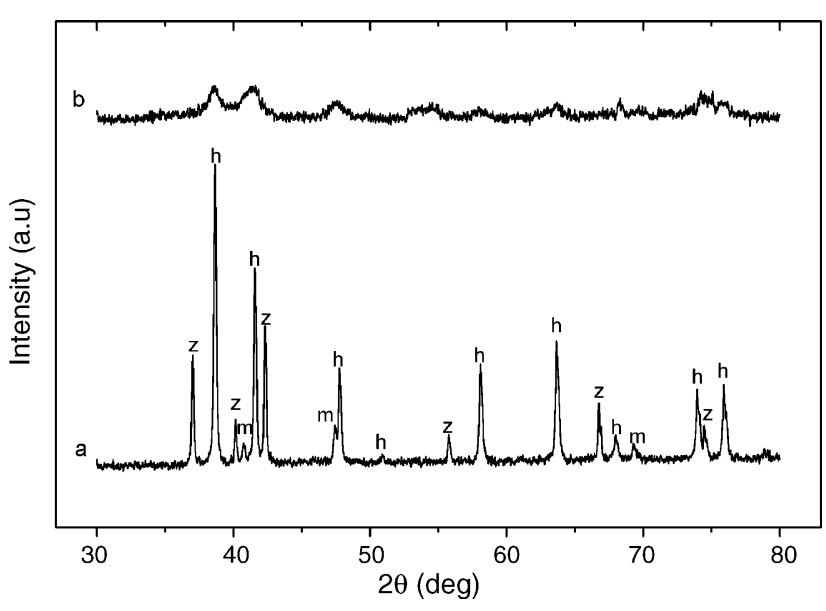

Fig. 1. XRD diagrams of the non-activated (a) and activated (b) sample A65. h: Hematite $\left(\mathrm{Fe}_{2} \mathrm{O}_{3}\right)$; $\mathrm{z}$ : zincite $(\mathrm{ZnO})$ and $\mathrm{m}$ : byxbite $\left(\mathrm{Mn}_{2} \mathrm{O}_{3}\right)$.

\section{Results and discussion}

\subsection{Series $A$}

Fig. 1 shows the X-ray diffractograms of the nonactivated (a) and activated (b) samples A65. A notable widening and a significant decrease of the peaks intensity can be observed, as a consequence of the loss of crystallinity of the reactants structures and the decrease of crystallite size, caused by the mechanochemical treatment. For the other compositions (A50 and A85), similar results were obtained.

Although by examining the XRD patterns of the activated samples it is not possible to identify the formation of $\mathrm{MnZn}$ ferrite, the VSM analyses (Fig. 2) reveal the presence of a magnetic phase with very low saturation magnetisation (Ms) and low coercivity (Hc). This could be attributed to the partial formation of the corresponding mixed ferrite. The very low registered values of Ms could be caused by a defective crystalline structure of the ferrimagnetic phase (which is just formed) and/or by a small concentration of this mixed ferrite. This hypothesis was confirmed after carrying

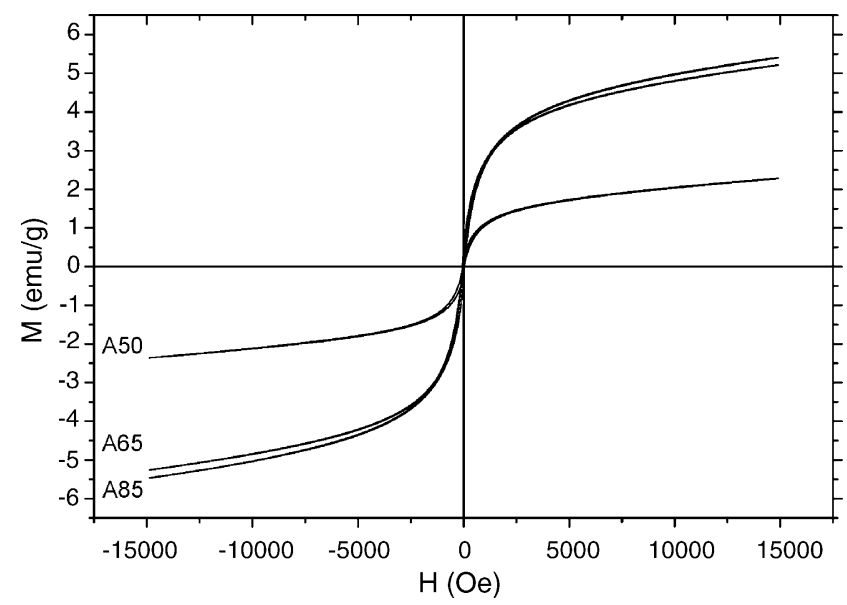

Fig. 2. VSM hysteresis loops for activated samples A50, A65 and A85. out longer mechanical activations of Series A samples. When powders A50 and A85 were milled for $2 \mathrm{~h}$, they showed a significant increment of $\mathrm{Ms}$, reaching 9.5 and $12.4 \mathrm{emu} / \mathrm{g}$, respectively. If these values are compared with those obtained from Fig. 2, it is clear that during the activation the formation of the mixed ferrites took place.

In Fig. 3 XRD diagrams of Series A heated at $1100{ }^{\circ} \mathrm{C}$ (a) and $1200{ }^{\circ} \mathrm{C}$ (b) are shown. At $1100{ }^{\circ} \mathrm{C}$, the complete conversion to the corresponding ferrite in each case $\left(\mathrm{Mn}_{0.5} \mathrm{Zn}_{0.5} \mathrm{Fe}_{2} \mathrm{O}_{4}, \mathrm{Mn}_{0.65} \mathrm{Zn}_{0.35} \mathrm{Fe}_{2} \mathrm{O}_{4}\right.$ and $\mathrm{Mn}_{0.85} \mathrm{Zn}_{0.15} \mathrm{Fe}_{2} \mathrm{O}_{4}$ ) can be noticed, without the presence of the starting oxides. The diffractograms of the samples calcined at $1200{ }^{\circ} \mathrm{C}$ reveal both an increase of the intensity and a peak narrowing, due to an increment in grain size. At both temperatures, a decrease of the diffracted intensity with increasing content of $\mathrm{Mn}$ is observed. This effect is not caused by a more defective structure of the Mn-richest ferrites, but by the relatively high absorption coefficient of $\mathrm{Mn}$ for the used $\mathrm{Co} \mathrm{K} \alpha$ radiation. Fig. 4 shows the lattice parameters calculated for all the synthesised samples. A very good agreement with the values reported for similar
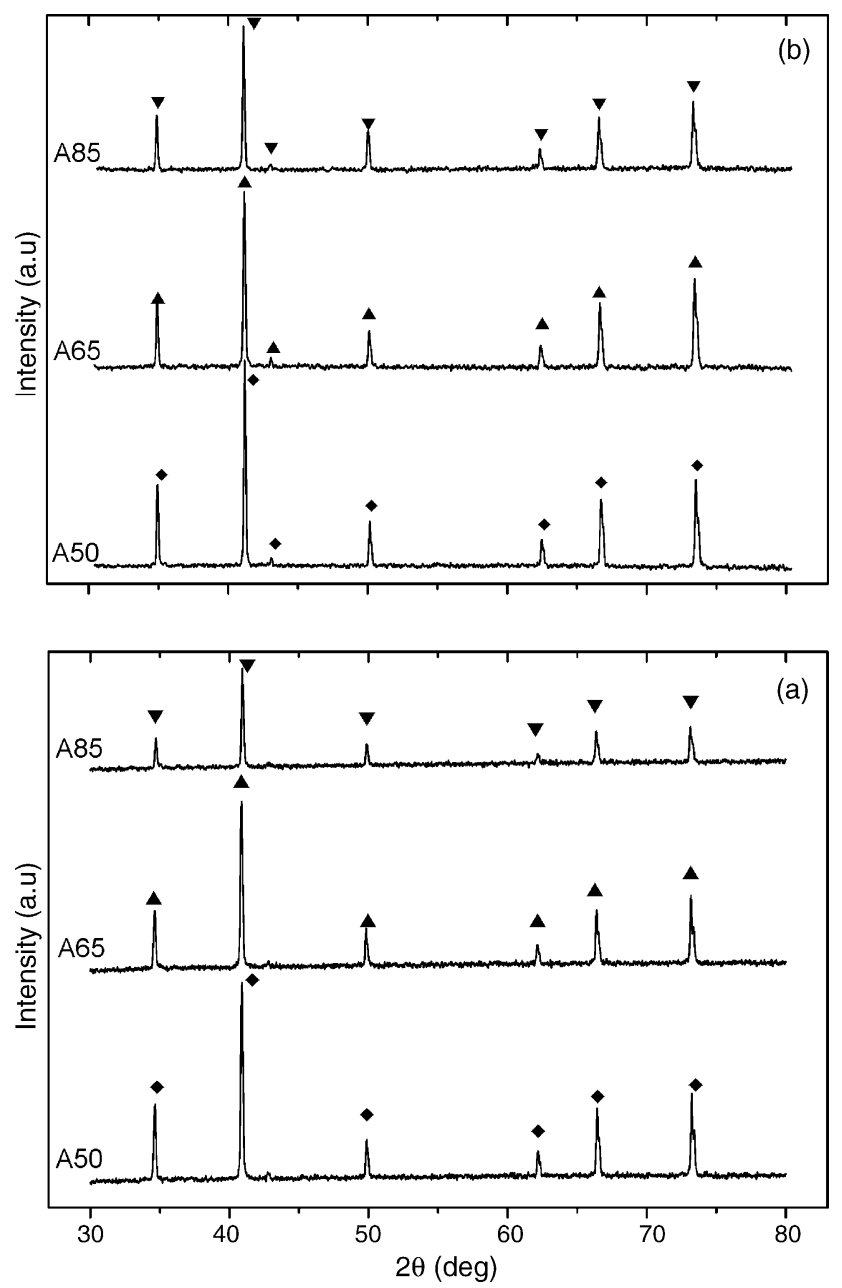

Fig. 3. XRD diagrams of samples A50, A65 and A85 calcined at $1100{ }^{\circ} \mathrm{C}$ (a) and $1200{ }^{\circ} \mathrm{C}$ (b) under $\mathrm{N}_{2}$ atmosphere. $(\diamond) \mathrm{Mn}_{0.5} \mathrm{Zn}_{0.5} \mathrm{Fe}_{2} \mathrm{O}_{4}$; ( $\mathrm{Mn}_{0.65} \mathrm{Zn}_{0.35} \mathrm{Fe}_{2} \mathrm{O}_{4} ;(\boldsymbol{\nabla}) \mathrm{Mn}_{0.85} \mathrm{Zn}_{0.15} \mathrm{Fe}_{2} \mathrm{O}_{4}$. 


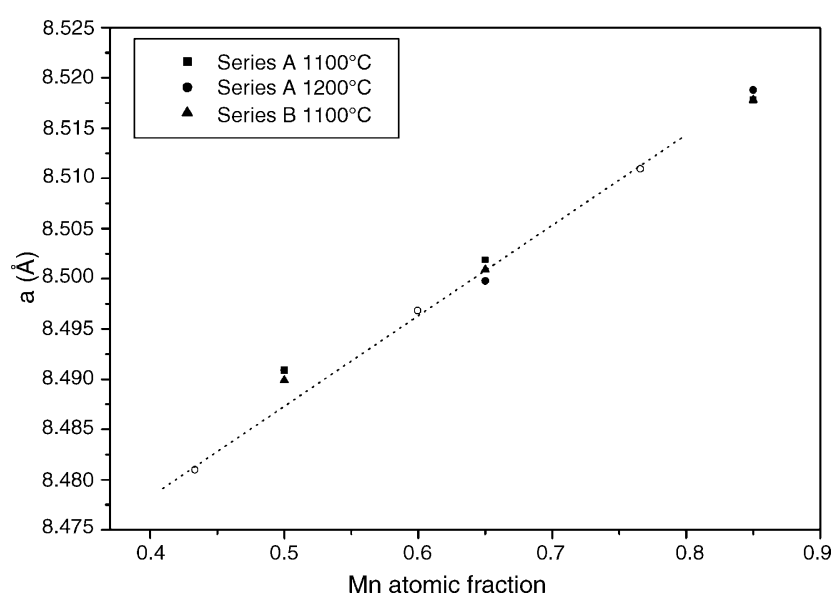

Fig. 4. Correlation between lattice parameter (a) calculated for the ferrites synthesised by both methods (filled symbols) and the corresponding theoretical values (open circles) according to ICSD [18]. The line is drawn only as a guide. compositions in ICSD [18] is observed, confirming the good crystallisation of the obtained ferrites. Significant differences between parameters calculated for samples calcined at 1100 and $1200{ }^{\circ} \mathrm{C}$ are not observed.

The determination of densities for the ferrites prepared at $1100{ }^{\circ} \mathrm{C}$ resulted in values ranged between 85 and $90 \%$ of the corresponding theoretical values. Thermal treatment at $1200{ }^{\circ} \mathrm{C}$ improved the average densities of the ferrites, achieving densities between 90 and $95 \%$. The microstructures of these materials can be observed in Fig. 5. At $1100{ }^{\circ} \mathrm{C}$, the micrographs show a homogeneous morphology and a grain size of about 2-5 $\mu \mathrm{m}$ (Fig. 5a). A higher heating temperature $\left(1200{ }^{\circ} \mathrm{C}\right)$ led to a significant grain coarsening, reaching approximately in average $10 \mu \mathrm{m}$ (Fig. 5b). Moreover, at both temperatures larger grains can be noticed for the Mn-richer materials; this microstructural difference is especially noticeable in samples A50 and A65. In this way, the content of Mn seems to have an influence on the sintering rate.
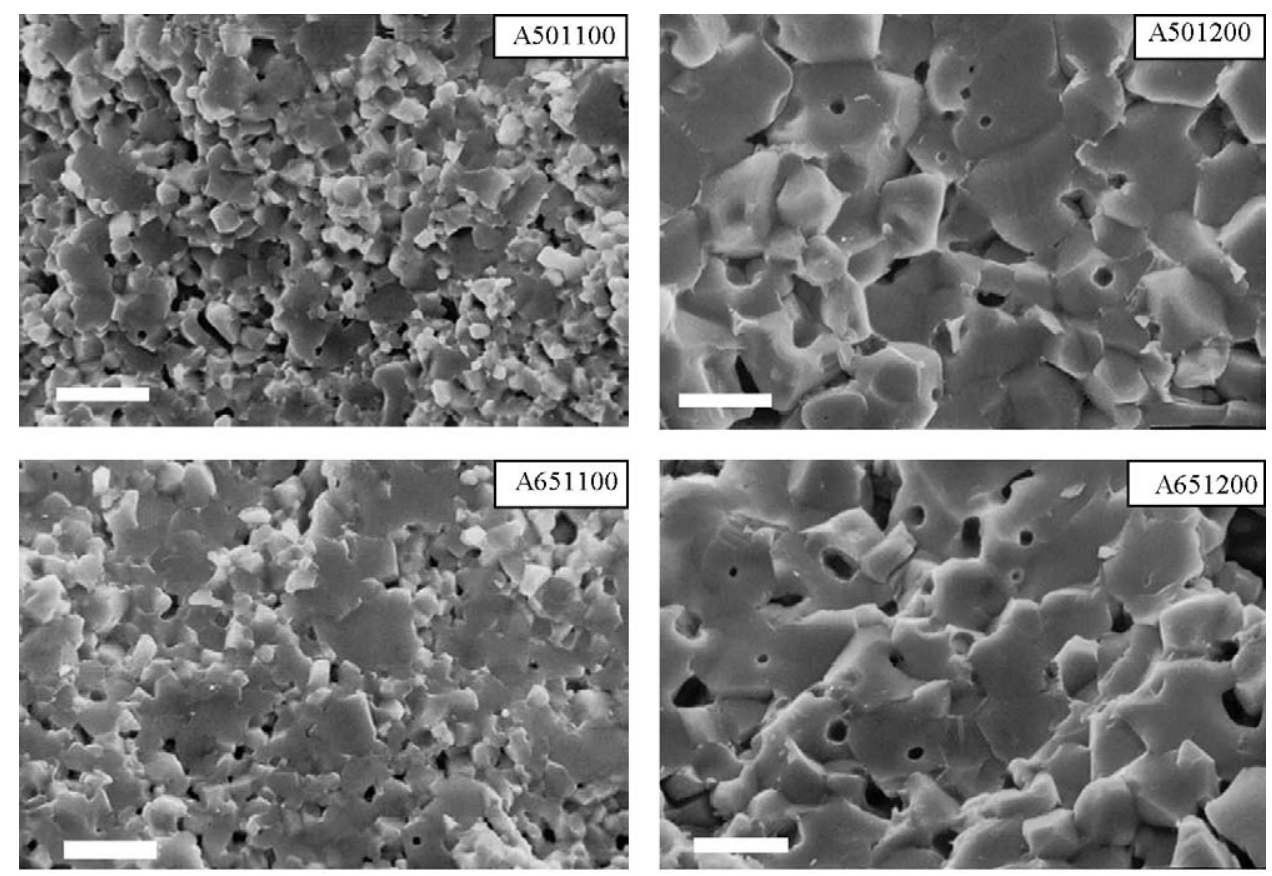

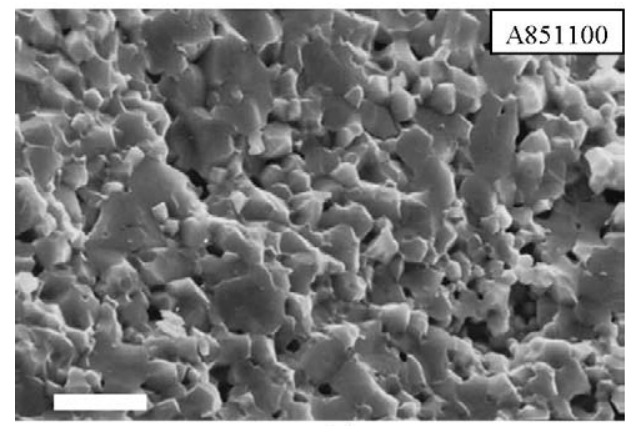

(a)

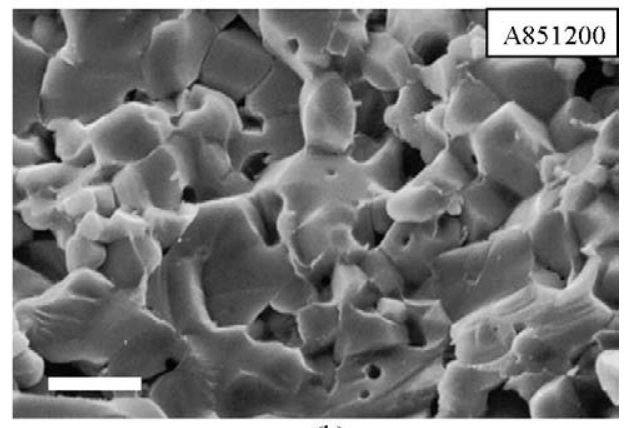

(b)

Fig. 5. SEM micrographs of the samples of Series A, heated at $1100{ }^{\circ} \mathrm{C}$ (a) and $1200{ }^{\circ} \mathrm{C}(\mathrm{b})$. Bar: $10 \mu \mathrm{m}$. 

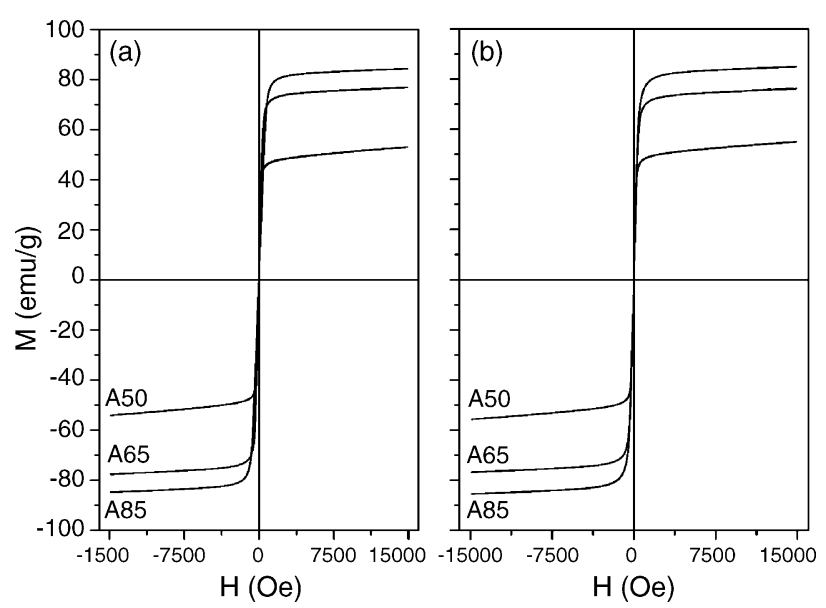

Fig. 6. VSM analyses for the samples A50, A65 and A85 calcined at $1100{ }^{\circ} \mathrm{C}$ (a) and $1200{ }^{\circ} \mathrm{C}(\mathrm{b})$

Fig. 6 displays the hysteresis loops obtained by VSM for samples A50, A65 and A85 calcined during $1 \mathrm{~h}$ at 1100 (a) and $1200{ }^{\circ} \mathrm{C}$ (b). Taking into account the loops obtained for the as-activated samples (Fig. 2), it can be concluded that the thermal treatment produced an important increment of $\mathrm{Ms}$, which is due to the complete formation of the MnZn ferrite for the three compositions. Also, a decrease of Hc can be seen, as a result of the crystallite size growth undergone during the thermal treatment. Table 2 summarises Ms and Hc values taken from the magnetic measurements corresponding to the calcined samples. All the Ms values are very close to the reported in the literature for each ferrite [19]. Materials with higher $\mathrm{Mn}$ content give the highest percentages of theoretical Ms, which could be related to the better sintering and the presence of larger grains in Mnricher compositions. The measured coercivities are very low, as was expected for these soft magnetic materials. Thermal treatment at $1200{ }^{\circ} \mathrm{C}$ produced little changes in the magnetic properties of the obtained materials. However, an increment of Ms and a decrease of Hc values are observed, which is in good agreement with the increase of grain size observed by XRD and VSM.

EPMA analysis revealed that the elemental starting composition was not modified during the thermal treatments. The integration of signals belonging to $\mathrm{Zn}$ and $\mathrm{Mn}$ made possible to estimate the mass percentages of each element in the sample. For the sample A50 heated at

Table 2

Ms and Hc values obtained from VSM analyses for samples A50, A65 and A85 heated at 1100 and $1200{ }^{\circ} \mathrm{C}$

\begin{tabular}{lllll}
\hline Sample & Hc (Oe) & $\begin{array}{l}\text { Experimental } \\
\text { Ms (emu/g) }\end{array}$ & $\begin{array}{l}\text { Theoretical } \\
\text { Ms (emu/g) }\end{array}$ & $\begin{array}{l}\text { \% Theoretical } \\
\text { Ms }\end{array}$ \\
\hline A50-1100 & 4 & 53.0 & 60.0 & 88.3 \\
A65-1100 & 6 & 76.9 & 77.0 & 99.9 \\
A85-1100 & 7 & 84.3 & 86.0 & 98.0 \\
A50-1200 & 4 & 55.0 & 60.0 & 91.7 \\
A65-1200 & 5 & 76.4 & 77.0 & 99.2 \\
A85-1200 & 5 & 85.0 & 86.0 & 98.8 \\
\hline
\end{tabular}

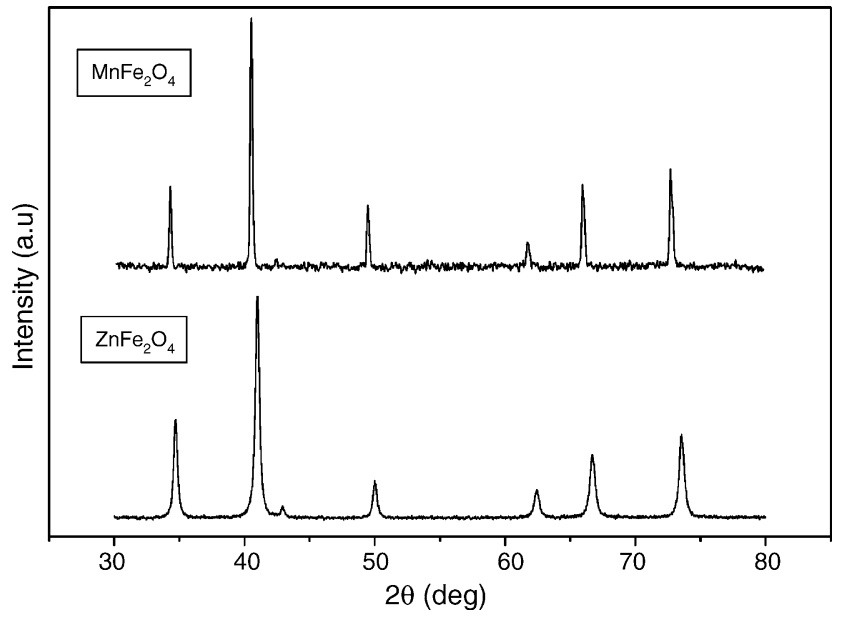

Fig. 7. XRD patterns of the synthesised $\mathrm{ZnFe}_{2} \mathrm{O}_{4}$ and $\mathrm{MnFe}_{2} \mathrm{O}_{4}$.

$1200{ }^{\circ} \mathrm{C}$, this calculation gives $20.7 \% \mathrm{Zn}$ and $17.4 \% \mathrm{Mn}$, which results in a $\mathrm{Zn} / \mathrm{Mn}$ weight ratio of 1.19 . If this value is compared with the theoretical $\mathrm{Zn} / \mathrm{Mn}$ weight ratio corresponding to $\mathrm{Mn}_{0.5} \mathrm{Zn}_{0.5} \mathrm{Fe}_{2} \mathrm{O}_{4}$ (1.20), it can be concluded that there is no evaporation of $\mathrm{Zn}$ from the ferrite structure during the treatment at $1200{ }^{\circ} \mathrm{C}$. A probable explanation for this fact is that the formation reaction of MnZn ferrites is fast enough to avoid the $\mathrm{Zn}$ loss. This is an important result because one of the most common problems of the sintering of $\mathrm{MnZn}$ ferrites is the evaporation of $\mathrm{Zn}$, since the associated changes of composition make difficult to adequately control the magnetic properties [20].

\subsection{Series $B$}

The XRD diagrams of the previously synthesised $\mathrm{ZnFe}_{2} \mathrm{O}_{4}$ and $\mathrm{MnFe}_{2} \mathrm{O}_{4}$ (Fig. 7) show the presence of a unique crystalline phase, without remaining starting oxides. These powders were employed for preparing $\mathrm{ZnFe}_{2} \mathrm{O}_{4}-$ $\mathrm{MnFe}_{2} \mathrm{O}_{4}$ mixtures (Series $\mathrm{B}$ ), whose compositions are given in Table 1.

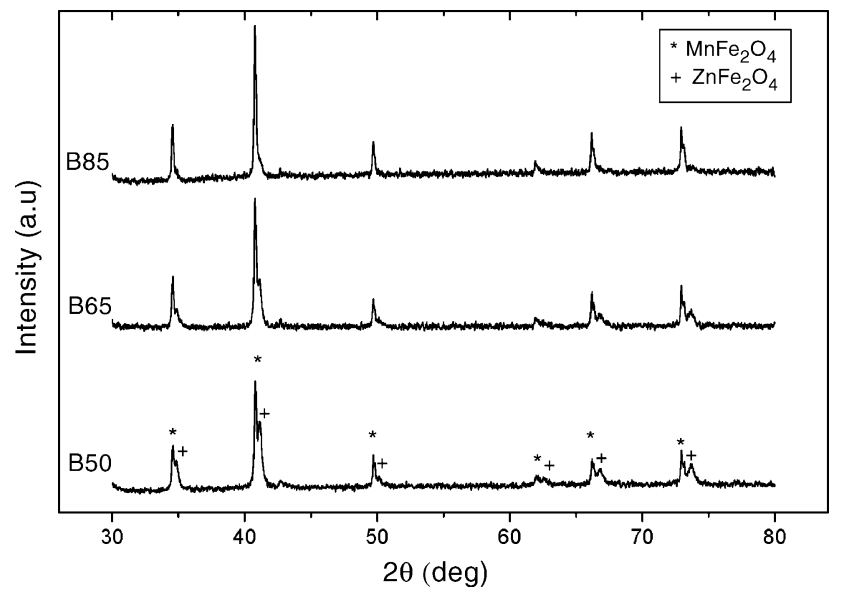

Fig. 8. XRD diagrams of the as-mixed samples B50, B65 and B85. 


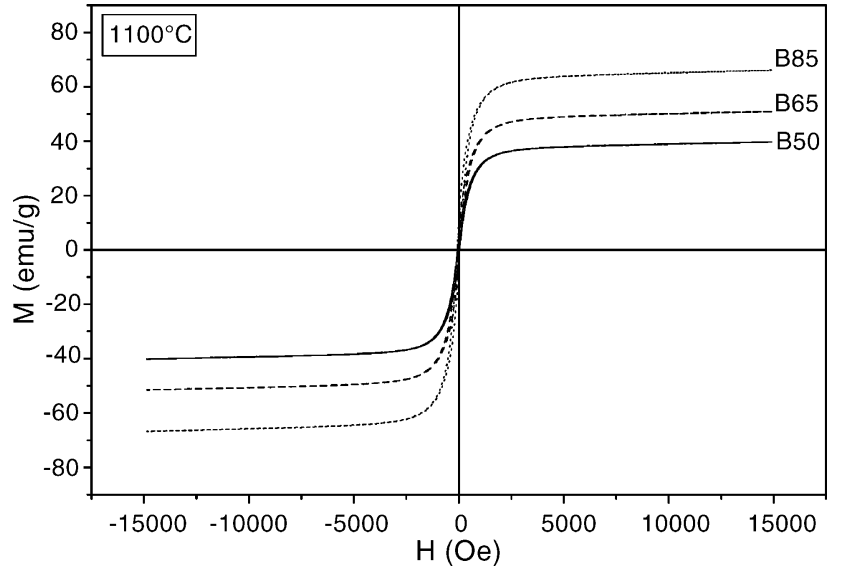

Fig. 9. VSM hysteresis loops of the as-mixed samples B50, B65 and B85.

The powder mixtures B50, B65 and B85 were characterised by XRD and VSM (Figs. 8 and 9, respectively). For the three compositions, the presence of both well-crystalline single ferrites can be observed, suggesting that the mechanical mixing did not produce relevant changes on the structure of the previously obtained $\mathrm{ZnFe}_{2} \mathrm{O}_{4}$ and $\mathrm{MnFe}_{2} \mathrm{O}_{4}$. In the hysteresis loops, a gradual increase of $\mathrm{Ms}$ can be seen. This was expectable, considering the theoretical values of Ms reported for each ferrite. Taking into account the mass percentages of $\mathrm{ZnFe}_{2} \mathrm{O}_{4}$ and $\mathrm{MnFe}_{2} \mathrm{O}_{4}$ that contains each mixture, the Ms values per gram of $\mathrm{MnFe}_{2} \mathrm{O}_{4}$ were calculated from the measured Ms values for each sample. These calculations give between 78 and $79 \mathrm{emu} / \mathrm{g}$ for the three compositions, which are very close to that reported at room temperature for $\mathrm{MnFe}_{2} \mathrm{O}_{4}(78.5 \mathrm{emu} / \mathrm{g})$, corroborating that the mechanical mixing has not produced significant damage in the crystalline structure of the single ferrites.

Fig. 10 shows the XRD diagrams of samples B50, B65 and B85 calcined for $1 \mathrm{~h}$ at $1100{ }^{\circ} \mathrm{C}$. For the three compositions, a complete conversion to each ferrite can be observed. Moreover, the obtained lattice parameters

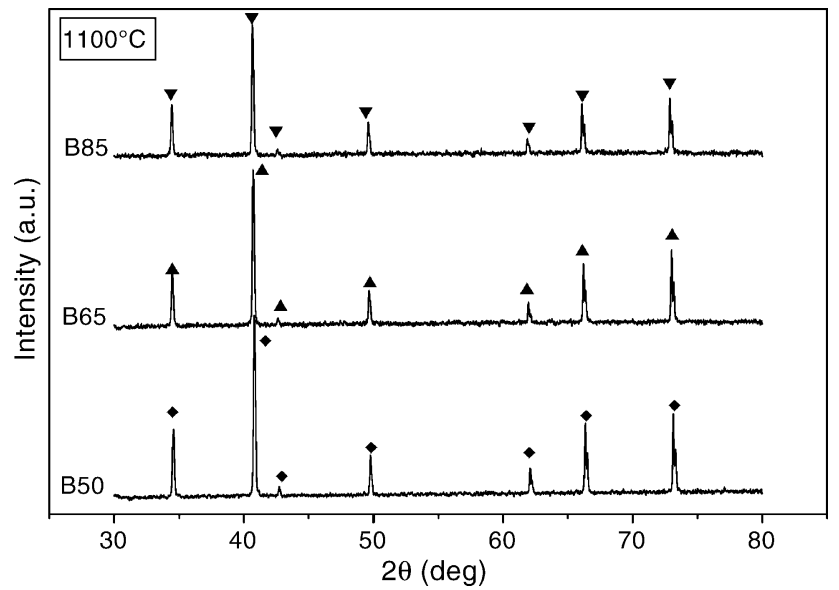

Fig. 10. XRD diagrams of samples B50, B65 and B85 calcined at $1100{ }^{\circ} \mathrm{C}$ under $\mathrm{N}_{2}$ atmosphere. $(\diamond) \mathrm{Mn}_{0.5} \mathrm{Zn}_{0.5} \mathrm{Fe}_{2} \mathrm{O}_{4} ;(\boldsymbol{\Delta}) \mathrm{Mn}_{0.65} \mathrm{Zn}_{0.35} \mathrm{Fe}_{2} \mathrm{O}_{4} ;(\boldsymbol{\nabla})$ $\mathrm{Mn}_{0.85} \mathrm{Zn}_{0.15} \mathrm{Fe}_{2} \mathrm{O}_{4}$.
(Fig. 4) also agree with the expected values, without showing any significant differences with those obtained for samples from Series A. The complete formation to the mixed ferrites is confirmed by VSM. The Ms and Hc values obtained from the hysteresis loops are summarised in Table 3. Both properties are very close to the corresponding theoretical values. As in the case of Series A, the higher Mn content the higher percentage of theoretical Ms, which confirms the correlation between Ms and density in these ferrites. Comparing the magnetic properties for both series (Tables 2 and 3), it may be stated that the materials prepared by both techniques have a similar magnetic behaviour.
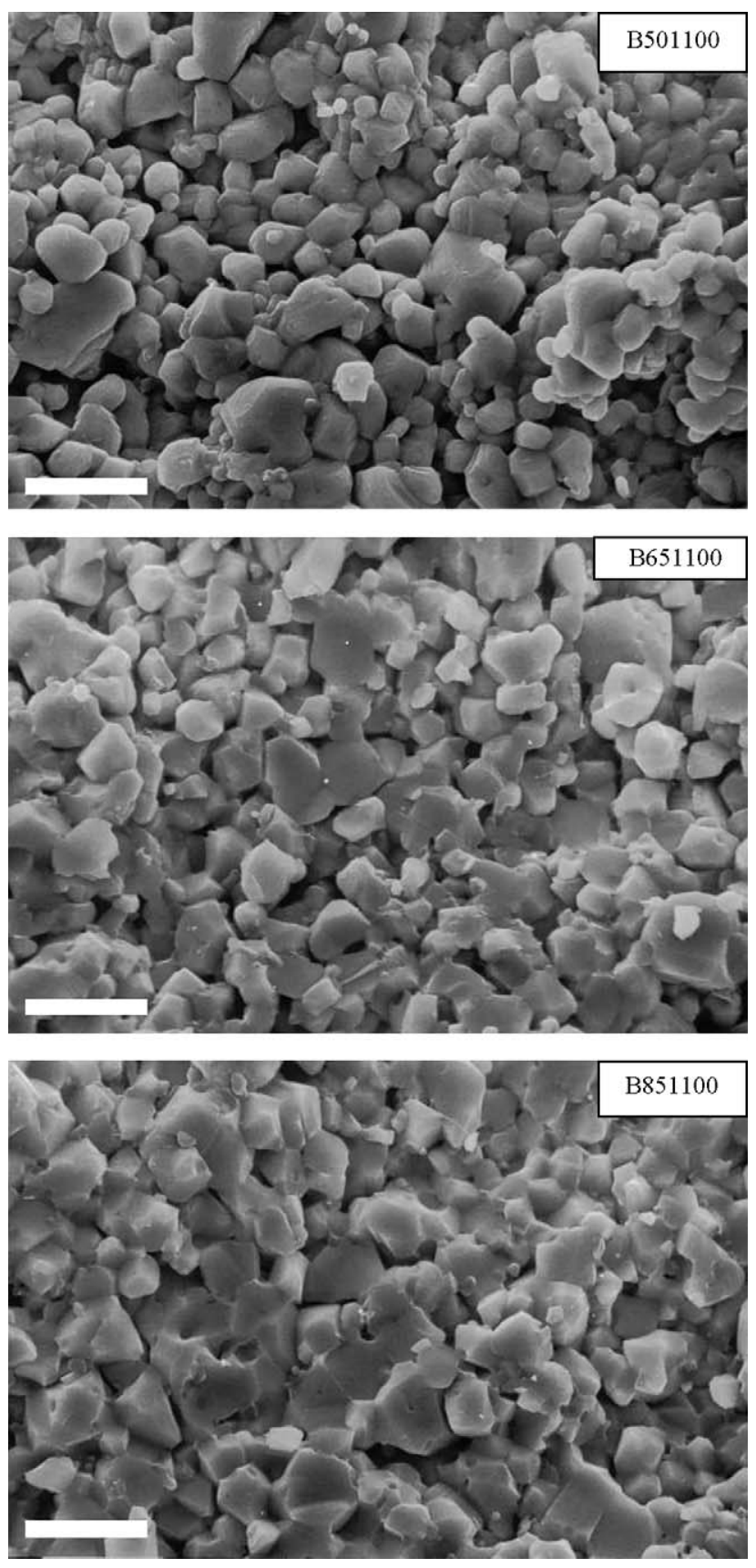

Fig. 11. SEM micrographs of samples B50, B65 and B85 calcined at $1100{ }^{\circ} \mathrm{C}$. Bar: $10 \mu \mathrm{m}$. 
Table 3

Ms and Hc values obtained from VSM analyses for samples B50, B65 and B85 heated at $1100{ }^{\circ} \mathrm{C}$

\begin{tabular}{lllll}
\hline Sample & Hc (Oe) & $\begin{array}{l}\text { Experimental } \\
\text { Ms }(\mathrm{emu} / \mathrm{g})\end{array}$ & $\begin{array}{l}\text { Theoretical } \\
\text { Ms }(\mathrm{emu} / \mathrm{g})\end{array}$ & $\begin{array}{l}\text { \% Theoretical } \\
\text { Ms }\end{array}$ \\
\hline B50-1100 & 4 & 53.5 & 60.0 & 89.2 \\
B65-1100 & 4 & 74.4 & 77.0 & 96.6 \\
B85-1100 & 5 & 84.6 & 86.0 & 98.4 \\
\hline
\end{tabular}

The microstructures of Series B materials are shown in Fig. 11. A higher sintering degree and a grain size growth as the Mn content increases can be noticed. These micrographs also show that the sintering of Series B is less complete than that of Series A. In fact, density measurements for these materials resulted in values between 80 and $85 \%$ of theoretical densities which means-in average- $5 \%$ lower than those of the materials obtained from Series A. The difference in the compaction degree between the powders of Series A and B, could be due to the fact that the first ones were compacted asmilled powders and the last ones were thermally treated (in order to form the single ferrites) prior to the uniaxial pressing.

\section{Summary}

Two experimental methods to prepare $\mathrm{Mn}_{x} \mathrm{Zn}_{1-x} \mathrm{Fe}_{2} \mathrm{O}_{4}$ ferrites $(x=0.50,0.65$ and 0.85$)$ were developed:

- Starting from the mechanochemical activation of the elemental oxides and ulterior thermal treatment at $1100{ }^{\circ} \mathrm{C}$ and $1200{ }^{\circ} \mathrm{C}$ under $\mathrm{N}_{2}$ atmosphere (Series A).

- Starting from a mechanical mixture of $\mathrm{MnFe}_{2} \mathrm{O}_{4}$ and $\mathrm{ZnFe}_{2} \mathrm{O}_{4}$ and ulterior thermal treatment at $1100{ }^{\circ} \mathrm{C}$ (Series B).

Materials obtained at $1100{ }^{\circ} \mathrm{C}$ from Series A have densities between 85 and $90 \%$ of theoretical density, whereas the ferrites produced by the other method have lower densities. The magnetic properties of both series of materials were very similar, reaching high saturation magnetisation values (close to the theoretical ones) and low coercivities.

Thermal treatment at $1200{ }^{\circ} \mathrm{C}$ notably enhances the sintering of ferrites prepared from Series A, resulting in densities between 90 and $95 \%$ of theoretical densities. It is worth mentioning that these densities were reached at short times and relatively low temperatures without the use of sintering aids. In addition, evaporation of $\mathrm{Zn}$ from the ferrite structure was not detected during calcination, which enables an increase of the thermal treatment temperature in order to optimise the material densities.

Although both synthesis routes led to the production of the mixed MnZn ferrites, the method used in Series A appears to be more convenient, since starting from the elemental oxides and through an extremely simple two-step processing, soft MnZn ferrites with good magnetic properties have been obtained.

\section{Acknowledgements}

The authors thank CONICET, CIC, UNMdP and UNC for the financial support given to this work. The valuable contribution from Fundación Antorchas to the collaboration between the authors is specially acknowledged.

\section{References}

[1] M. Sugimoto, The past, present and future of ferrites, J. Am. Ceram. Soc. 82 (1999) 269-280.

[2] M. Rozman, M. Drofenik, Sintering of nanosized MnZn ferrite powders, J. Am. Ceram. Soc. 81 (1998) 1757-1764.

[3] M.I. Rosales, A.M. Plata, M.E. Nicho, A. Brito, M.A. Ponce, V.M. Castaño, Effect of sintering conditions on microstructure and magnetic properties of Mn-Zn ferrites, J. Mater. Sci. 30 (1995) 4446-4450.

[4] Y. Chien, Y. Ko, Dependence of magnetic properties of Mn-Zn ferrites on the degree of calcination, J. Mater. Sci. 26 (1991) 5859-5864.

[5] J. Fan, F.R. Sale, The microstructures, magnetic properties and impedance analysis of $\mathrm{Mn}-\mathrm{Zn}$ ferrites doped with $\mathrm{B}_{2} \mathrm{O}_{3}$, J. Eur. Ceram. Soc. 20 (2000) 2743-2751.

[6] G. Ott, J. Wrba, R. Lucke, Recent developments of Mn-Zn ferrites for high permeability applications, J. Magn. Magn. Mater. 254-255 (2003) 535-537.

[7] A.C. Razzitte, S. Jacobo, W.G. Fano, Magnetic properties of MnZn ferrites prepared by soft chemical routes, J. Appl. Phys. 87 (2000) 6232-6234.

[8] A. Thakur, M. Singh, Preparation and characterization of nanosize $\mathrm{Mn}_{0.4} \mathrm{Zn}_{0.6} \mathrm{Fe}_{2} \mathrm{O}_{4}$ ferrite by citrate precursor method, Ceram. Int. 29 (2003) 505-511.

[9] K. Mandal, S. Pan Mandal, P. Agudo, M. Pal, A study of nanocrystalline $(\mathrm{Mn}-\mathrm{Zn})$ ferrite in $\mathrm{SiO}_{2}$ matrix, Appl. Surf. Sci. 82 (2001) 386389.

[10] X. Jiao, D. Chen, Y. Hu, Hydrothermal synthesis of nanocrystalline $\mathrm{M}_{x} \mathrm{Zn}_{1-x} \mathrm{Fe}_{2} \mathrm{O}_{4}(\mathrm{M}=\mathrm{Ni}, \mathrm{Mn}, \mathrm{Co} ; x=0.40-0.60)$ powders, Mater. Res. Bull. 37 (2002) 1583-1588.

[11] A. Kosak, D. Makovec, A. Znidarsic, M. Drofenik, Preparation of $\mathrm{MnZn}$-ferrite with microemulsion technique, J. Eur. Ceram. Soc. 24 (2004) 959-962.

[12] C. Suryanarayana, E. Ivanov, V.V. Boldyrev, The science and technology of mechanical alloying, Mater. Sci. Eng. A 304-306 (2001) 151158.

[13] K. Tkácová, Mechanical Activation of Minerals, Elsevier Science, The Netherlands, 1989.

[14] P.M. Botta, P.G. Bercoff, E.F. Aglietti, H.R. Bertorello, J.M. Porto López, Magnetic and structural study of mechanochemical reactions in the $\mathrm{Al}-\mathrm{Fe}_{3} \mathrm{O}_{4}$ system, J. Mater. Sci. 37 (2002) 2563-2568.

[15] D.J. Fatemi, V.G. Harris, V.M. Browning, J.P. Kirkland, Processing and cation distribution of MnZn ferrites via high-energy ball milling, J. Appl. Phys. 83 (1998) 6867-6869.

[16] D.J. Fatemi, V.G. Harris, M.X. Chen, S.K. Malik, W.B. Yelon, G.J. Long, A. Mohan, X-ray absorption, neutron diffraction, and Mössbauer effect studies of MnZn-ferrite processed through high-energy ball milling, J. Appl. Phys. 85 (1999) 5172-5174.

[17] P.M. Botta, P.G. Bercoff, E.F. Aglietti, H.R. Bertorello, J.M. Porto López, Preparación y caracterización de ferritas $\mathrm{MnZn}$ a partir de mezclas de $\mathrm{ZnFe}_{2} \mathrm{O}_{4}$ y $\mathrm{MnFe}_{2} \mathrm{O}_{4}$, Matéria 9 (2004) 144-150.

[18] Inorganic Crystal Structure Database 2004, CCod 28514, 28515 and 28516.

[19] J. Smit, H.P.J. Wijn, Ferrites, John Wiley \& Sons, The Netherlands, 1959 , pp. 156-160.

[20] Q. Yan, R.J. Gambino, S. Sampath, L.H. Lewis, L. Li, E. Baumberger, A. Vaidya, H. Xiong, Effects of zinc loss on the magnetic properties of plasma-sprayed MnZn ferrites, Acta Mater. 52 (2004) 3347-3353. 